\title{
HIV Prevention in Papua New Guinea: Is It Working or Not?
}

\author{
Heather Worth \\ School of Public Health \& Community Medicine, University of New South Wales, Sydney, Australia. \\ Email: h.worth@unsw.edu.au
}

Received April 17 ${ }^{\text {th }}$ 2012; revised May 23 ${ }^{\text {rd }}, 2012$; accepted June $5^{\text {th }}, 2012$

\begin{abstract}
Introduction: There is a global call for structural approaches to HIV that go beyond awareness and HIV testing to approach prevention work via the social and economic drivers of the epidemic. Papua New Guinea is the epicentre of the HIV epidemic in the Pacific, with an adult prevalence rate of $0.9 \%$. Since 2004, there has been a concerted response to HIV, with vastly increased rates of HIV testing and roll-out of antiretroviral therapy, and considerable funding for HIV prevention. Objectives: While incidence is slowing there are still a considerable number of new infections each year and many commentators are worried that HIV prevention is not working in that country. This article aims to critically examine HIV prevention programs in Papua New Guinea to show whether HIV prevention is effectiveness in reaching those most vulnerable to infection. Methods: Using data from HIV prevention programs and behavioural surveys this article will assess how HIV prevention has been carried out and the effectiveness of those programs. Results: There is little evidence to indicate that HIV prevention in Papua New Guinea, particularly among those most at risk of HIV has been successful. Conclusion: There is a dearth of HIV prevention interventions in Papua New Guinea that go beyond awareness-raising to deal with the structural drivers of the epidemic.
\end{abstract}

Keywords: HIV Prevention; Papua New Guinea; Aids-Awareness; HIV Drivers; Structural Interventions

\section{Introduction}

While Papua New Guinea (PNG) is the wealthiest country in the Pacific (due mainly to resource extraction) it has a low HDR index score and is unlikely to meet many of the Millennium Development Goals by 2015. PNG is also the epicentre of HIV in the Pacific with an estimated adult prevalence of $0.9 \%$ [1]. HIV spread is heterogeneous with the Highlands region and the National Capital District carrying a higher burden of infection. The data on HIV incidence in PNG is interesting. Figure 1 indicates that there has been a steep rise in new infections from 2000, with a sharp drop in 2007 and a slower rise again in 2009 and 2010 [2]. This signifies a slowing of the epidemic in PNG although it is too early to tell what is causing HIV to slow.

In terms of its HIV response, PNG has been successful in vastly increasing HIV testing-from 1407 in 2004 to 138,581 in 2010. It has also increased access to antiretroviral therapy (from 80 people on ART in 2004 to 8522 in 2010). However, there are major supply chain issues, drug stock-outs, and human resource issues to contend with as well as financing of ART in the future [3]. ART may account for what appears to be a slowing of the epidemic. There is considerable evidence to indicate that
ART lowers viral load and thus infectivity [4-6].

But while PNG has seen a slowing in the numbers of diagnoses, there are still substantial numbers of people becoming infected with HIV each year. Thus HIV prevention still remains the most important strategy to respond to HIV in PNG.

There is considerable expenditure on HIV in Papua New Guinea. AusAID is the dominant donor for HIV and AIDS activities in PNG. In 2010, AusAID provided 76 percent of total HIV funding of over AUD 53 million [7]. HIV prevention represents 21 per cent of AusAID funding through government and non-governmental organization (NGO) partners since 2006. It is estimated that the expenditure by AusAID alone on HIV prevention from 2011-2015 will be in the region of \$3 billion, [7].

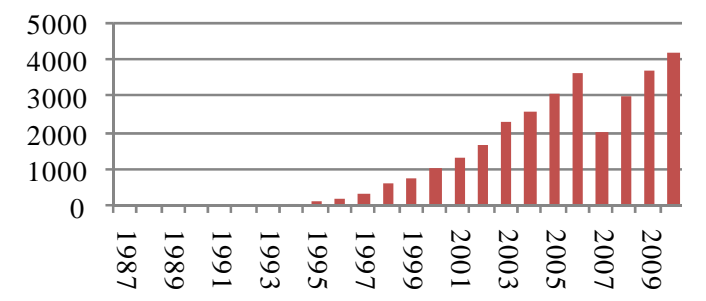

Figure 1. New HIV Diagnoses, Papua New Guinea 19872010. 
Given large amounts of HIV prevention funding to Papua New Guinea since the early 200s, is HIV prevention working in PNG?

\section{Methods}

In order to assess the effectiveness of HIV prevention programs in PNG, we: 1) undertook an online search of the two "major" HIV prevention programs that have operated since 2007 in PNG-AusAID’s Tingim Laip project which supports people in high risk settings who may be more vulnerable to HIV and those funded by PNGAustralia HIV and AIDS Program (PAHAP) to see what they said they did in terms of HIV prevention; 2) we reviewed all published evaluations and assessments of these programs; and 3) examined them in the light of available behavioural change data for vulnerable groups (sex workers and men who have sex with men) over time. The Tingim Laip project, which is the AusAID response to high risk settings) received AUD10 million from 2007-2010 [8], while PAHAP provided AU\$20.4 million in 2009 to sixteen international non-government organizations funded for service delivery, Australian-based international organizations, as well as PNG faith-based organizations and local civil society organizations though this mechanism.

While PAHAP-funded activities and Tingim Laip's program do not represent all the HIV prevention activity in Papua New Guinea, together they represent the overwhelming majority of activity. Tingim Laip (Phase 1) was Papua New Guinea's (PNG) largest communitybased HIV prevention strategy targeting behaviour change interventions with vulnerable populations in settings where HIV transmission was known or likely to be high. Key features included: empowering vulnerable communities to develop, implement and monitor their own responses to HIV; and developing partnerships with government departments, the private sector and civil society (non-government organizations, community based organizations and faith-based organizations) in both rural and urban settings.

\section{Results}

\subsection{HIV Prevention Program Information}

We found that data on the PAHAP-funded projects were extremely hard to access. We could find very little detailed information about most of the programs, including budget. What we did find indicated that while they often offered a range of services, much of the work was small-scale and siloed. It was mainly concentrated (with a few exceptions) on raising awareness and/or HIV testing. While most claim to be carrying out HIV prevention activities, this could be as little as encouraging access to or provision of voluntary counselling and testing for
(VCT) HIV or “increasing HIV awareness”.

Tingim Laip (Phase 1), the largest of all the HIV prevention programs, operated in 36 sites in 11 provinces. The program was aimed at people and communities, to build capacity and empower communities at higher risk of HIV infection by providing them with knowledge, tools, and ongoing support to design and manage their own responses to the epidemic. It focused on men, women, and youth who congregate in "hotspots" where sex is negotiated: markets, lodgings, and entertainment sites along major highways and near ports; villages near mines, other industries, and military posts; and settlements around urban areas. While there was a considerable amount of description about the program there was very little publically-available detailed information about its success.

\subsection{Evaluations of Program Effectiveness}

For most of the PAHAP-funded organisations there were no available data on evaluation of their HIV prevention programs. However, the Papua New Guinea-Australia HIV and AIDS program: civil society engagement case study also reports that, "most partners are not contributing to a comprehensive approach to HIV prevention” p.6 [9]. The PNG Independent Review Group on HIV/ AIDS's (IRG) review in May 2011 was particularly concerned that HIV prevention among key populations such as sex workers, men who have sex with men and transgender people (most of which is funded under the PAHAP scheme) has not shown any appreciable scale up since 2010. For example, Poro Sapot's prevention work remains small-scale both in terms of numbers of people reached and geographical coverage. It was also concerned that there was little HIV prevention coverage at sites where there is a high convergence of risk.

The mid-term evaluation of Tingim Laip in 2007 shows mixed results [10]. The report showed that Tingim Laip had made inroads into harnessing community energy and partnerships, and had distributed large numbers of condoms. However, even though 17.9 million condoms were distributed by the National AIDS Council.

Secretariat (NACS) and Provincial AIDS Councils in 2010, up from 8 million in 2007, condom use continues to be low. The Independent Review Group (2010) [11] argue that that even in hotels and motels where condom distribution has been focused, HIV prevention does not have the intensity and coverage required. While Tingim Laip's brief was to focus on "hotspots" of HIV risk, the Independent Review Group (2011) report states that "A number of areas of high risk and vulnerability convergence-characterised by mobility and cash flow, latenight drinking and the availability of sex workers-are being missed in HIV prevention... [12]. In the context of 
upcoming development projects, many more sites of "high risk convergence" are likely to emerge [12]. Tingim Laip's mid-term review argued that it had a weak conceptual framework and did not report outcomes. Thus it was impossible to assess whether there was any resultant behaviour change.

AusAID's (draft) Evaluation of the Australian Aid Program's Contribution to the National HIV Response in Papua New Guinea indicates, "HIV prevention and education services have not moved beyond the work done in the mid-2000s. ... Most partners are not using methods that engage individuals and communities to change to healthier behaviours" [13]. This, despite the fact that international behaviour change evidence has demonstrated for several years that general awareness-raising alone does not change people's behaviour [14]. The IRG 2011report and the ODE review both found that most HIV prevention efforts lack an understanding of gender and few programs specifically engage in interventions to address gender-based violence, sexual coercion and rape, gender roles and relations, and gender power differentials.

\subsection{Evidence of Behavioural Change?}

While Papua New Guinea has claimed that it is experiencing a generalised epidemic, HIV infection appears to be considerably higher in sex workers and men who have sex with men than in the general population. From the few studies that have collected biological data amongst sex workers HIV prevalence ranged from 0\% (in Goroka and Kainantu-in 2003) to 19\% (in Port Moresby in 2010) (see Table 1) [15-17]. It must be noted that all but Kelly et al. [18] were convenience samples.

Table 1 indicates that there is no evidence that con- dom use has increased in sex worker populations. While there is a plethora of data which measures condom use with clients; but the methods used and the measurement of condom use vary considerably. However, the rates of condom use for every sexual act with a client in 1989$46 \%$ [19] has actually dropped by 2008-33\% [20] and in $2010-38 \%$ [18].

There is even less prevalence data available for male sex workers and for men who have sex with men. The Poro Sapot project indicated an HIV prevalence of 2.14\% [17] while Kelly et al.'s 2011 study recorded 8.8\% prevalence for male sex workers and $23.7 \%$ for transgender sex workers. The Poro Sapot project estimates that the HIV prevalence amongst their men who have sex with men was 4.35\%, [17], whereas for Hope Worldwide clients the prevalence was $7.28 \%$, [17].

It is extremely concerning that while there have been large amounts of funding for HIV prevention there is no evidence in PNG of sustained behaviour change amongst those most at risk of HIV.

\section{Discussion}

Concern has been raised by a number of scholars about the behavioural and structural impediments to HIV prevention efforts to date [21-25]. In the developing world, HIV prevention has been characterized as a "failure" by some... Some have argued for a shift in prevention priorities [26], with others [27] "unsatisfactory results” of interventions that rely on behaviour change account for the failure. Structural impediments to HIV prevention include factors in the social, economic and political environments that shape and constrain individual and community, health outcomes [28]—-those largely outside

Table 1. HIV prevalence amongst female sex workers in Papua New Guinea.

\begin{tabular}{|c|c|c|c|c|c|}
\hline Author & Date & Description & Place & Sample size & \% HIV+ \\
\hline Bruce et al., 2010 [15] & 2003 & $\begin{array}{c}\text { A cross sectional study of reported symptoms } \\
\text { for sexually transmissible infections among } \\
\text { female sex workers in PNG }\end{array}$ & Port Moresby & 129 FSW & $16.3 \%$ \\
\hline $\begin{array}{l}\text { Gare et al., } \\
2005 \text { [16] }\end{array}$ & 2003 & $\begin{array}{l}\text { High prevalence of sexually transmitted in- } \\
\text { fections among female sex workers in East } \\
\text { highland province of PNG: correlates \& rec- } \\
\text { ommendations }\end{array}$ & $\begin{array}{l}\text { Goroka \& } \\
\text { Kainantu }\end{array}$ & 211 FSW & $0 \%$ \\
\hline $\begin{array}{l}\text { UNGASS } 2010 \\
\text { (PoroSapot project } \\
\text { NCD ) }\end{array}$ & 2009 & $\begin{array}{c}\text { Papua New Guinea, UNGASS 2008, Country } \\
\text { progress report }\end{array}$ & NCD & 675 FSW & $7.4 \%$ \\
\hline $\begin{array}{l}\text { UNGASS } 2010 \text { (Hope } \\
\text { Worldwide NCD) [17] }\end{array}$ & $\begin{array}{l}2008 / \\
2009\end{array}$ & $\begin{array}{c}\text { Papua New Guinea, UNGASS 2008, Country } \\
\text { progress report }\end{array}$ & Port Moresby & 292 FSW & $11.3 \%$ \\
\hline Kelly et al. 2011 [18] & 2011 & $\begin{array}{l}\text { Askim Na Save (Ask and understand) People } \\
\text { who sell and exchange sex in Port Moresby }\end{array}$ & Port Moresby & 441 FSW & $19 \%$ \\
\hline
\end{tabular}


individual control [29]. Key structural factors influencing HIV transmission are gender inequity, poverty and migration [30]. Kippax et al. argue that changes in behaviour (or practice) require widespread social change. HIV prevention efforts need to go hand in hand with parallel efforts to promote social environments that are supportive of safer sexual behaviour [31-33], in order to provide contexts that increase people's power to protect their sexual health.

Many researchers as well as those involved in policy and program have agreed that social and structural approaches to preventing HIV become a core element. The key drivers of HIV vulnerability that affect the ability of individuals to protect themselves and others must be addressed in order for communities to respond effectively to the epidemic [34]. Papua New Guinea has key social forces that drive the epidemic. For example, Kathy Lepani has discussed the question of mobility as a structural driver of HIV, as well as the links between gender, sexuality and violence that are implicated in HIV transmission She argues that "in Papua New Guinea, enduring and pervasive patterns of male sexual behaviour involving coercion, violence and gang rape are highly conducive to the transmission of HIV" [35].

But have these palpable issues that link widespread social and economic change in PNG been taken up in HIV prevention programs in PNG? And has the forms of HIV prevention that exist in that country been successful? Commentators on the epidemic are concerned that the approach taken has "been largely both irrelevant and ineffective" [13]. The IRG found in 2010 that in Papua New Guinea there was "no serious HIV prevention work underway nationally or in the provinces to address the structural drivers of the epidemic. HIV prevention cannot be effective and at scale unless the broader structural determinants of the epidemic are addressed and a comprehensive approach is adopted" [11].

\section{Conclusion}

In 2011, the Governments of Papua New Guinea and Australia agreed to a new strategic direction for the aid program that focuses on delivering better health (including HIV and AIDS) and education outcomes, particularly at sub-national level. One of the priority outcomes related to HIV agreed to at the Ministerial Forum with PNG in 2011 was to "increase the percentage of men and women aged 15 to 59 who had more than one sexual partner in the past 12 months who report the use of a condom during last intercourse from 38.9 per cent to 80 per cent by 2015, and that 80 per cent of male and female sex workers report the use of a condom with their most recent client" [33]. In order for that to happen, HIV prevention work must be intensified and must use a comprehensive prevention approach. Apart from Tingim Laip
HIV prevention programs in Papua New Guinea seem to be a mixture of condom distribution, awareness-raising and VCT, all important but lacking a structural approach to the issue. They are mostly scattered, small-scale and largely ineffective with little coordination from Provincial AIDS Committees. Most evaluations argue that for HIV prevention to be effective in PNG it needs to tackle the major drivers of the epidemic: development, mobility and women's inequality.

\section{REFERENCES}

[1] UNGASS, "Papua New Guinea Country Progress Report,” 2010.

[2] National Department of Health (NDOH), “The 2010 STI, HIV and AIDS Annual Surveillance Report,” National Department of Health STI, HIV and AIDS Surveillance Unit, 2011.

[3] H. Worth, J. Rule, H. Buchanan, K. Browne, A. Amos, G. Roberts, R. Taylor and A. Razzaq, "HIV and Human Resources Challenges in Papua New Guinea (An Overview)," HRH Hub and IHRG, School of Public Health and Community Medicine, University of New South Wales, Sydney, 2012.

[4] R. M. Granich, C. F. Gilks, C. Dye, K. M. De Cock and B. G. Williams, "Universal Voluntary HIV Testing with Immediate Antiretroviral Therapy as a Strategy for Elimination of HIV Transmission: A Mathematical Model," Lancet, Vol. 373, No. 9657, 2009, pp. 48-57.

[5] M. Das, P. L. Chu, G. M. Santos, et al., "Decreases in Community Viral Load Are Accompanied by Reductions in New HIV Infections in San Francisco," PLoS One, Vol. 5, 2010, Article ID: e11068. doi:10.1371/journal.pone.0011068

[6] J. S. Montaner, V. D. Lima, R. Barrios, et al., “Association of Highly Active Antiretroviral Therapy Coverage, Population Viral Load, and Yearly New HIV Diagnoses in British Columbia, Canada: A Population-Based Study,” Lancet, Vol. 376, 2010, pp. 532-539. doi:10.1016/S0140-6736(10)60936-1

[7] AusAID, “Evaluation of the Australian Aid Program's Contribution to the National HIV Response in Papua New Guinea,” Draft 2, Office of Development Effectiveness, AusAID, Canberra, 2011.

[8] AusAID, "Evaluation of the PNG National HIV/AIDS support Project," Review Series No. 38, AusAID, Canberra, 2005. http://www.hivpolicy.org/Library /HPP000726.pdf

[9] AusAID, “The 2010 Papua New Guinea-Australia HIV and AIDS Program: Civil Society Engagement Case Study,” Office for Development Effectiveness, AusAID, Canberra, 2011.

[10] Heywood and S. Martin, "Independent Evaluation of Tingim Laip,” Draft Final Report, 2007.

[11] Independent Review Group on HIV/AIDS, "Report from an Assessment Visit 22 April-5 May 2010,” Papua New Guinea, 2010. 
[12] Independent Review Group on HIV/AIDS, "Report from an Assessment Visit 28 April-13 May 2011,” Papua New Guinea, 2011.

[13] AusAID, "Evaluation of the Australian Aid Program's Contribution to the National HIV Response in Papua New Guinea," Draft 2, Office of Development Effectiveness, AusAID, Canberra, 2011.

[14] International Federation of Red Cross and Red Crescent Societies, "Standards for HIV Peer Education Programmes," Geneva, 2009.

[15] E. Bruce, L. Bauai, A. Masta, P. J. Rooney, M. Paniu, et al., "A Cross-Sectional Study of Reported Symptoms for Sexually Transmissible Infections among Female Sex Workers in Papua New Guinea," Sexual Health, Vol. 7, No. 3, 2010, pp. 71-76. doi:10.1071/SH09093

[16] J. Gare, T. Lupiwa, D. Suarkia, M. Paniu, A. Wahasoka, H. Nivia, J. Kono, W. Yeka, J. Reeder and C. Mgone, "High Prevalence of Sexually Transmitted Infections among Female Sex Workers in the Eastern Highlands Province of Papua New Guinea: Correlates and Recommendations," Sexually Transmitted Diseases, Vol. 32, No. 8, 2005, pp. 466-473. doi:10.1097/01.olq.0000161177.21639.96

[17] A. Kelly, M. Kupul, Y. N. Wing, S. Nosi, N. Lote, P. Rawstorne, G. Halim, C. Ryan and H. Worth, “Askim na Save (Ask and Understand) People Who Sell and Exchange Sex in Port Moresby," University of New South Wales, Sydney, 2011.

[18] S. Mgone, M. Passey, J. Anang, W. Peter, T. Lupiwa, B. D. Russel, et al., "Human Immunodeficiency Virus and Other Sexually Transmitted Infections among Female Sex Workers in Two Major Cities in Papua New Guinea," Sexually Transmitted Disease, Vol. 29, No. 5, 2002, pp. 265-270. doi:10.1097/00007435-200205000-00003

[19] H. Aruwafu, F. Kupe and F. Akuani, "Bio-Behavioural Sentinel Surveillance Survey among Men and Women Attending Lae Friends STI Clinic 2008 Port Moresby,” NRI and NDoH, 2012.

[20] S. Kippax, E. Reis and J. D. Wit, "Two Sides to the HIV Prevention Coin: Efficacy and Effectiveness Source,” AIDS Education and Prevention, Vol. 23, No. 5, 2011, pp. 393-396. doi:10.1521/aeap.2011.23.5.393

[21] J. Ogden, G. Gupta, W. Fisherc and A. Warnerd, "Revolutionising the AIDS Response," Global Public Health, Vol. 6, 2011, pp. S383-S395. doi:10.1080/17441692.2011.621965

[22] J. Auerbach, "Transforming Social Structures and Environments to Help in HIV Prevention: Cost-Effective Interventions with Proven or Promising Results from Empowering Women to Providing Stable Housing for the Homeless,” Health Affairs, Vol. 28, No. 6, 2009, pp. 1655-
1655. doi:10.1377/hlthaff.28.6.1655

[23] G. Gupta, "HIV Prevention 4: Structural Approaches to HIV Prevention,” Lancet, Vol. 372, No. 9640, 2008, pp. 764-764. doi:10.1016/S0140-6736(08)60887-9

[24] R. Parker, D. Easton and C. Klein, "Structural Barriers and Facilitators in HIV Prevention: A Review of International Research,” AIDS, Vol. 14, No. 9, 2000, pp. S22S32. doi:10.1097/00002030-200006001-00004

[25] M. Potts, D. Halperin, A. Swidler, E. Marseille, J. Klausner, N. Hearst, R. Wamai, J. Kahn and J. Walsh, "Reassessing HIV Prevention,” Science, Vol. 320, No. 5877, 2008, pp. 749-750. doi:10.1126/science. 1153843

[26] F. Maggiolo and S. Leone, "Is HAART Modifying the HIV Epidemic?” The Lancet, Vol. 376, 2010, pp. 492493. doi:10.1016/S0140-6736(10)61057-4

[27] T. Rhodes, M. Singer, P. Bourgois, S. Friedman and S. Strathdee, "The Social Structural Production of HIV Risk among Injecting Drug Users,” Social Science \& Medicine, Vol. 61, 2005, pp. 1026-1044. doi:10.1016/j.socscimed.2004.12.024

[28] E. Sumartojo, "Structural Factors in HIV Prevention: Concepts, Examples, and Implications for Research," AIDS, Vol. 14, No. s2, 2000, pp. S3-S10. doi:10.1097/00002030-200006001-00002

[29] R. Parker, D. Easton and C. Klein, "Structural Barriers and Facilitators in HIV Prevention: A Review of International Research,” AIDS, Vol. 14, No. 9, 2000, pp. S22S32. doi:10.1097/00002030-200006001-00004

[30] C. Beeker, C. G. Guenther and A. Raj, "Community Empowerment Paradigm and the Primary Prevention of HIV/AIDS," Social Science and Medicine, Vol. 46, No.7, 1998, pp. 831-842. doi:10.1016/S0277-9536(97)00208-6

[31] O. Tawil, A. Verster and K. O’reilly, "Enabling Approaches for HIV/AIDS Promotion: Can We Modify the Environment and Minimize the Risk?” AIDS, Vol. 9, 1995, pp. 1299-1306.

[32] C. R. Waldo and T. J. Coates, "Multiple Levels of Analysis and Intervention in HIV Prevention Science: Examplars and Directions for New Research,” AIDS, Vol. 14, No. s2, 2000, pp. s18-s26.

[33] C. Campbell, A. Foulis, S. Maimane and Z. Sibiya, “The Impact of Social Environments on the Effectiveness of Youth HIV Prevention: A South African Case Study,” AIDS Care: Psychological and Socio-Medical Aspects of AIDS/HIV, Vol. 17, No. 4, 2005, pp. 471-478.

[34] L. Kathy, "Mobility, Violence and the Gendering of HIV in Papua New Guinea," The Australian Journal of Anthropology, Vol. 19, No. 2, 2008, pp. 150-164. doi:10.1111/j.1835-9310.2008.tb00119.x 